\title{
Histopathological validation of safe margin for nephron-sparing surgery based on individual tumor growth pattern
}

Gang $\mathrm{Li}^{1+}$, Tengfei Xiao ${ }^{2 \dagger}$, Keruo Wang ${ }^{1+}$, Renya Zhang ${ }^{3}$, Aixiang Wang ${ }^{4}$, Chengzhi Yan ${ }^{5^{*}}$ (D and Chunhui Wang ${ }^{1,6^{*}}$

\begin{abstract}
Background: To evaluate the clinicopathologic value of morphological growth patterns of small renal cell carcinoma (sRCC) and determine the actual demand for taking a rim of healthy parenchyma to avoid positive SM.

Methods: Data was collected from 560 sRCC patients who underwent laparoscopic surgeries from May 2010 to October 2017. One hundred forty-nine cases received nephron-sparing surgery (NSS) and others received radical nephrectomy (RN). All specimens were analyzed separately by two uropathologists, and three morphological growth patterns were identified. The presence of pseudocapsule (PC), surgical margins (SM), and other routine variables were recorded. The relationship between growth patterns and included variables was measured by the $x^{2}$ test and Fisher's exact probability test. Survival outcomes were evaluated by Kaplan-Meier method and the log-rank test.

Results: The median age of patients was 63.2 years old and the mean tumor diameter was $3.0 \mathrm{~cm}$. Four hundred eighty (85.7\%) cases were clear cell RCC and 541 (96.6\%) cases were at the pT1a stage. Peritumoral PC was detected in 512 (92.5\%) specimens, and the ratio of tumor invasion in PC in infiltration pattern increased obviously than that of the other growth patterns. Similarly, the pT stage was significantly correlated with the infiltration pattern as well. One hundred forty-nine patients underwent NSS and 3 (2.0\%) of them showed positive SM after operation. Statistical differences of the 5-year overall survival (OS) and the cancer-specific survival (CSS) existed between different morphological growth patterns, PC status, and pT stages.
\end{abstract}

Conclusions: Morphological growth patterns of sRCC might be used as a potential biomarker to help operate NSS to avoid the risk of positive SM. How to distinguish different morphological growth patterns before operation and the effectiveness of the growth pattern as a novel proposed parameter to direct NSS in sRCC patients deserves further exploration.

Keywords: Renal cell carcinoma, Pathology, surgical, Nephrectomy, Surgical margin, Survival analysis

\footnotetext{
*Correspondence: 6905114714@qq.com; 15004765949@163.com

${ }^{+}$Gang Li, Tengfei Xiao and Keruo Wang contributed equally to this work.

${ }^{5}$ Tianjin Baodi Hospital of Tianjin Medical University, Tianjin 301800, China

'Department of Urology, The Second Hospital of Tianjin Medical University,

Tianjin Institute of Urology, Tianjin 300211, China

Full list of author information is available at the end of the article
}

\section{$\triangle B M C$}

(c) The Author(s). 2021 Open Access This article is licensed under a Creative Commons Attribution 4.0 International License, which permits use, sharing, adaptation, distribution and reproduction in any medium or format, as long as you give appropriate credit to the original author(s) and the source, provide a link to the Creative Commons licence, and indicate if changes were made. The images or other third party material in this article are included in the article's Creative Commons licence, unless indicated otherwise in a credit line to the material. If material is not included in the article's Creative Commons licence and your intended use is not permitted by statutory regulation or exceeds the permitted use, you will need to obtain permission directly from the copyright holder. To view a copy of this licence, visit http://creativecommons.org/licenses/by/4.0/ The Creative Commons Public Domain Dedication waiver (http://creativecommons.org/publicdomain/zero/1.0/) applies to the data made available in this article, unless otherwise stated in a credit line to the data. 


\section{Background}

RCC is one of the most malignant tumors among genitourinary diseases, and significant progress in treatments has been achieved during the past 20 years. NSS has been widely confirmed as an effective measure for sRCC $[1,2]$, and the number of sRCC patients who accepted NSS has increased significantly in recent years. Nevertheless, no research had clarified the histopathological and clinical features of different kinds of morphological growth patterns of sRCC. For this regard, a more practicable classification and treatment strategy that could be utilized for choosing proper therapeutic methods for sRCC patients is necessary. A better understanding of the diverse growth patterns of sRCC, including their intricate characteristic, might bring about novel prognostic and therapeutic prospects.

Generally, the growth of tumor can be broadly divided into two groups according to the morphology of tumor and parenchyma relationship: the expansive growth pattern and the infiltrative pattern [3]. Relevant studies have shown that the layer of connective fibrous tissue termed tumor $\mathrm{PC}$, located at the interface between the tumor and adjacent renal parenchyma [1,4], and in some cases, the presence of tumor PC invasion, has been considered poor prognostic outcome for RCC $[5,6]$. In the past few years, several studies have indicated a reduction of the thickness of safety margins that should be excised with tumor to avoid local recurrence, while some researchers considered the thickness of resection margin is irrelevant with disease progression $[7,8]$. Nevertheless, the existence of tumor PC is not a standard parameter for pathological analysis so far.

In the present study, we analyzed 560 patients with sRCC (no cystic RCC included) and identified three major sRCC morphological growth patterns based on the growth types and features of peritumoral PC, indicating biological and oncological differences: single nodular pattern (SNP), multinodular fusion pattern (MFP), and infiltration pattern (IP).

The objective of this retrospective study was to evaluate the clinicopathologic value of different histological growth patterns, characterize peritumoral PC in sRCC, and define the optimal resection margin of healthy parenchyma individually, for avoiding the risk of positive SM.

\section{Subjects and methods \\ Subjects}

In this multi-center retrospective study, a total of 560 consecutive patients (416 males and 144 females) diagnosed with sRCC and underwent kidney surgeries by laparoscopy from May 2010 to October 2017 (patients with hereditary RCC were not included) were included, with the median age of $63.2 \pm 11.1$ years $(17-85)$, as
Table 1 Clinicopathologic characteristics

\begin{tabular}{|c|c|}
\hline Characteristic & Value \\
\hline No. of patients & 560 \\
\hline \multicolumn{2}{|l|}{ Age (years) } \\
\hline Range & $17-85$ \\
\hline Median & 63.2 \\
\hline \multicolumn{2}{|l|}{ Sex } \\
\hline Male & $416(74.3 \%)$ \\
\hline Female & $144(25.7 \%)$ \\
\hline \multicolumn{2}{|l|}{ sRCC subtype } \\
\hline Clear cell & $480(85.7 \%)$ \\
\hline Chromofobe & $38(6.8 \%)$ \\
\hline Papillary & $26(4.6 \%)$ \\
\hline Others & 16 (2.9\%) \\
\hline \multicolumn{2}{|l|}{ Growth pattern } \\
\hline SNP & 438 (78.2\%) \\
\hline MFP & $58(10.4 \%)$ \\
\hline $\mathbb{I P}$ & $64(11.4 \%)$ \\
\hline \multicolumn{2}{|l|}{ pT stage } \\
\hline $1 a$ & 541 (96.6\%) \\
\hline $3 a$ & 19 (3.4\%) \\
\hline \multicolumn{2}{|l|}{ Fuhrman grade } \\
\hline 1 & 137 (24.5\%) \\
\hline 2 & $370(66.1 \%)$ \\
\hline 3 & $42(7.5 \%)$ \\
\hline 4 & 11 (1.9\%) \\
\hline \multicolumn{2}{|l|}{$P C$} \\
\hline Absent & 48 (7.5\%) \\
\hline Present & 512 (92.5\%) \\
\hline
\end{tabular}

sRCC Small renal cell carcinoma, SNP A single nodular pattern, MFP A multinodular fusion pattern, IP An infiltration pattern, $P T$ Pathologic tumor, PC Pseudocapsule

shown in Table 1. The major clinical symptoms included gross hematuria (37 patients), microscopic hematuria (96), and renal area pain (55), and the other 338 cases showed no obvious symptoms (not shown in the table). All patients included in the study received preoperative computed tomography $(\mathrm{CT})$ or magnetic resonance imaging (MRI) of the abdomen, a chest $\mathrm{x}$-ray, and ultrasonography of the urinary system. Four patients were identified with multiple lesions in the lung and diagnosed as RCC lung metastasis. The mean tumor diameter was $3.0 \pm 0.6 \mathrm{~cm}(0.5-4.0 \mathrm{~cm}), 46$ cases were $<2.0$ $\mathrm{cm}, 123$ were $2.0-3.0 \mathrm{~cm}$, and 391 were $3.1-4.0 \mathrm{~cm}$, respectively. Overall, 149 (26.6\%) cases received NSS and the other $411(73.4 \%)$ received RN. The decision to proceed NSS or RN depended on the patients' preoperative imaging results, medical history, age, patient preference, and physician counseling. 


\section{Histological assessment}

The tumor size, integrity of peritumoral PC, and infiltration status of renal parenchyma were observed by morphological examination and then fixed in a $10 \%$ formalin solution. The growth pattern of the tumor was assessed on archival $4 \mu \mathrm{m}$ HE-stained tissue sections cut from formalin-fixed paraffin-embedded specimens from the tumor-kidney boundary. In order to standardize the materials, only the tissue section with the highest representation of the interface was examined. All specimens were analyzed separately by two dedicated uropathologists and cases in doubt were judged through the consensus review.

\section{Statistical analysis}

The $\chi^{2}$ test and Fisher's exact probability test were utilized to compare the relationship between growth patterns and clinical or pathological variables. A $p$ value $<$ 0.05 was considered statistically significant. The statistical calculations were performed using SPSS version 22.0 (SPSS, Chicago, IL). For survival statistics, the Kaplan-Meier method was used to estimate the 5-year OS and CSS, and the log-rank test was conducted to compare the groups of patients with respect to the $\mathrm{pT}$ stage, growth patterns, and PC invasion. The survival curves were plotted with Graphpad Prism 8.0.1.

\section{Results}

\section{Characteristics of tumor growth patterns}

The 560 renal tumor specimens were classified into three different growth patterns, with the examples shown in Fig. 1. We defined the three growth patterns of sRCC as follows: (I) SNP, only one entire tumor lesion exists in the kidney and the margin between tumor and renal parenchyma is clearly visible, and intact peritumoral PC could be observed in most of this type of sRCC (Fig. 1A-C); (II) MFP, several masses fuse into a large, well-defined, irregularly shaped mass, which usually separate from each other with connective fibrous tissues, and most of MFP tumors have complete peritumoral PC (Fig. 1D-F); and (III) IP, the tumor involves with poorly circumscribed margins with cancer cells extensively infiltrating and unequivocally entrapping normal kidney parenchyma, or the presence of normal renal tissue in the tumor, regardless of tumor circumscription (Fig. 1G-I). The peritumoral PC was defined as a band of fibrous connective tissues located at the interface between the tumor and adjacent parenchyma or adjacent tumors. Positive SM was defined as tumor reaching the edge of the specimen that was removed in the case of invasive tumor within $1 \mathrm{~mm}$ of the edge of the specimen. The tumor size, pathological subtype, tumor stage, Fuhrman grade, depth of tumor invasion, and other variables were also assessed entirely.
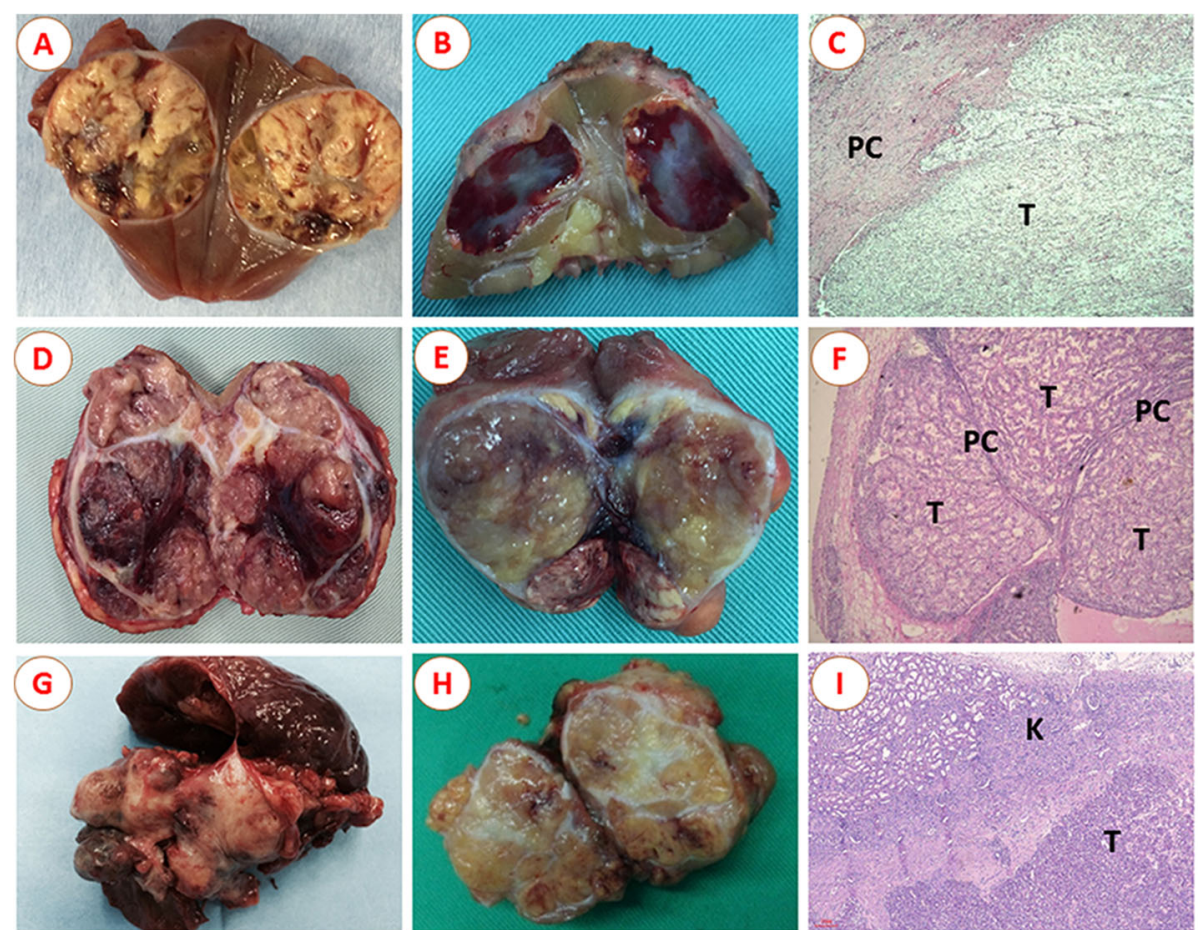

Fig. 1 Different morphological subtypes of small renal cell carcinoma (sRCC) after nephron-sparing surgery: A, B Single nodular growth pattern of SRCC and the H-E staining pathological specimen (C); D, E Multinodular fusion growth pattern of sRCC and H-E staining pathological specimen (F); G, H Infiltration growth pattern of sRCC and H-E staining pathological specimen (I). Abbreviations: T, tumor; PC, pseudocapsule; K, kidney 

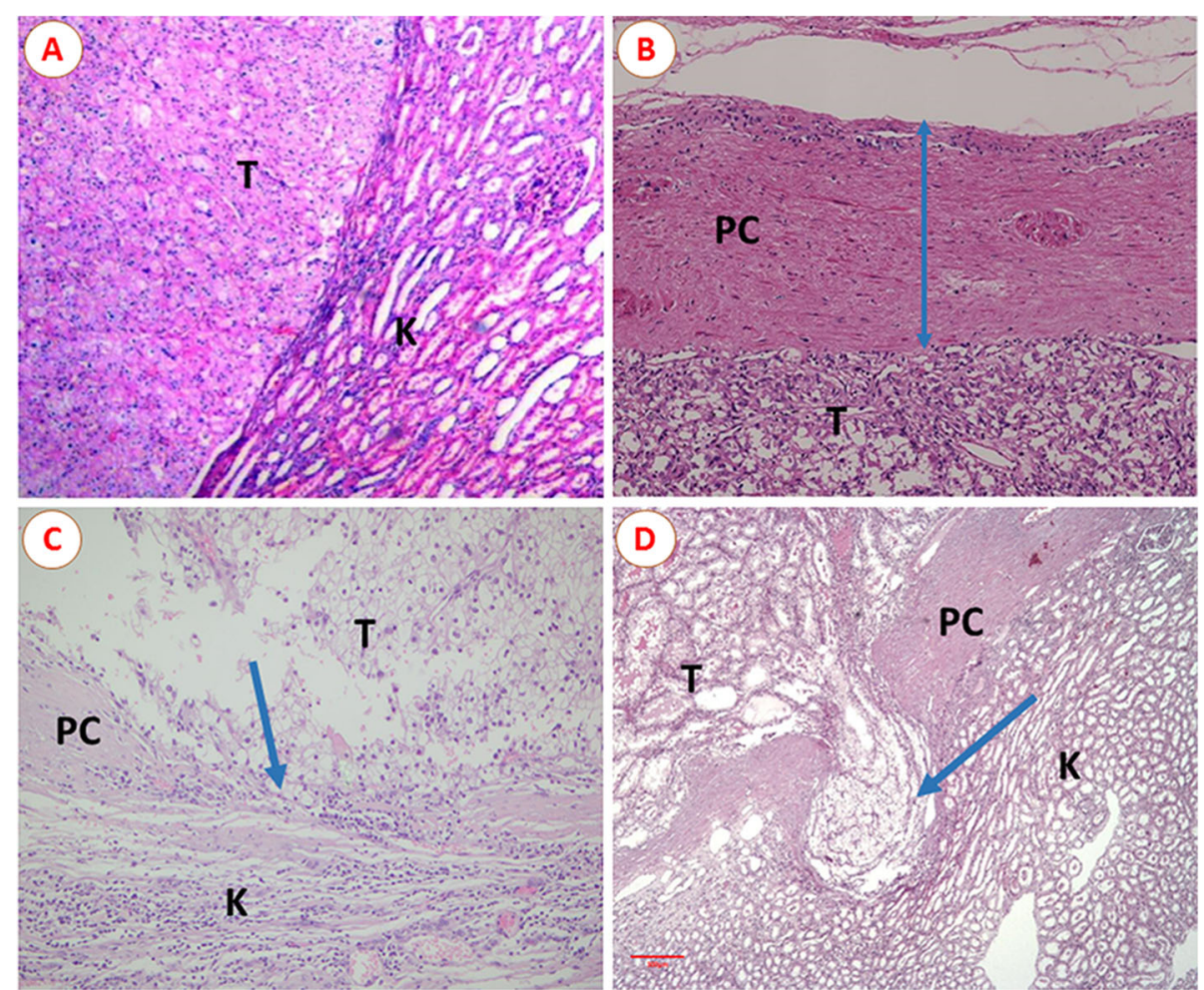

Fig. 2 A No pseudocapsule between tumor and renal parenchyma. B Pseudocapsule (PC) intact and without infiltration of tumor cells (invasion $(-)$ ). C PC infiltrated by tumor cells but with no invasion beyond it (invasion (+)). D PC with neoplastic infiltration beyond it (invasion (++)), with the depth of tumor invasion at about $14 \mathrm{~mm}$ (the scale bar: $300 \mu \mathrm{m}$ ). Abbreviations: T, tumor; K, kidney

\section{Classification of PC}

The specimen with no obvious peritumoral PC was shown in Fig. 2A. PC status could be further divided into three categories: $\mathrm{PC}$ intact and free from invasion (invasion (-), Fig. 2B), PC with neoplastic infiltration on the parenchymal kidney with no invasion beyond it (invasion (+), Fig. 2C), and PC with neoplastic infiltration and invasion beyond it (invasion (++), Fig. 2D).

\section{Baseline clinicaopathologic characteristics}

The descriptive clinicopathologic statistics for this study are provided in Table 1. A total of 560 patients were included, with the median age of 63.2 (17 to 85), in which 416 patients were males and the others were females. The histopathologic evaluation based on the 2004 WHO classification revealed that $480(85.7 \%)$ cases were clear cell RCC, 38 (6.8\%) were chromophobe RCC, 26 (4.6\%) were papillary RCC, and $16(2.9 \%)$ were other RCC subtypes. The SNP of tumors was found in $78.2 \%$ patients $(n=438)$, MFP in $10.4 \%(n=58)$, and IP in $11.4 \%(n=$ 64) of all patients.

The post-operative pathological analysis based on the TNM classification showed that $96.6 \%(n=541)$ of tumors were pT1a, and $3.4 \%(n=19)$ were at the pT3a stage, as the perirenal adipose was infiltrated by tumor cells. According to the Fuhrman nuclear grading, 24.5\% $(n=137)$ of the tumors were Grade I, $66.1 \%(n=370)$ were Grade II, 7.5\% ( $n=42)$ were Grade III, and $1.9 \%(n$ = 11) were Grade IV. The presence of peritumoral PC was detected in $512(92.5 \%)$ cases, and the rest of 48 (7.5\%) patients showed no obvious PC.

\section{Distribution of growth patterns in SRCC subtypes}

Table 2 showed the distribution of three growth patterns in different sRCC subtypes, and no statistical difference was found in such a situation $(p=0.941)$. According to the results, the distribution of three growth patterns was

Table 2 The distribution of three growth patterns in different sRCC subtypes

\begin{tabular}{lllll}
\hline $\begin{array}{l}\text { sRCC } \\
\text { subtype }\end{array}$ & \multicolumn{2}{l}{ Growth patterns } & \multirow{2}{*}{$\begin{array}{c}\boldsymbol{P} \\
\text { value }\end{array}$} \\
\cline { 2 - 4 } & SNP & MFP & IP & \\
\hline Clear cell & $378(78.8 \%)$ & $48(10.0 \%)$ & $54(11.2 \%)$ & 0.922 \\
Chromofobe & $29(76.3 \%)$ & $5(13.2 \%)$ & $4(10.5 \%)$ & \\
Papillary & $18(69.2 \%)$ & $4(15.4 \%)$ & $4(15.4 \%)$ & \\
Others & $13(81.3 \%)$ & $1(6.2 \%)$ & $2(12.5 \%)$ & \\
\hline
\end{tabular}

sRCC Small renal cell carcinoma, SNP A single nodular pattern, MFP A multinodular fusion pattern, IP An infiltration pattern 
SNP (69.2-81.3\%) > MFP(6.2-15.4\%) > IP(10.5-15.4\%) in all sRCC subtypes.

\section{Relationship of PC, PC invasion, pT stage, SM, and different growth patterns}

The results suggested that the presence of PC was significantly correlated with different morphological growth patterns $(p<0.001)$, and the absence of PC in IP $(43.8 \%)$ was obviously more frequent than the other two patterns (Table 3). PC status was also statistically associated with different growth patterns $(p<0.001)$ (Table 3$)$, the situation of invasion $(++)$ in IP was significantly higher than SNP $(p<0.001)$ and MFP $(p<0.001)$ (not shown in the table). In all specimens of invasion $(++)$, the mean depth of tumor invasion in renal parenchyma was $1.06 \mathrm{~mm}$ (SD: 0.22; median: 1.11; range: $0.30-2.6 \mathrm{~mm}$ ), the infiltrative depth in more than 95\% cases was limited in 2 $\mathrm{mm}$ and $100 \%$ in $3 \mathrm{~mm}$ beyond the surface of peritimoral PC.

A total of 19 patients were diagnosed with pT3a through post-operative pathological examination, in which 14 were found in IP cases. Table 3 showed that pT3a stage was statistically related to IP $(p<0.001)$, and the ratio of such stage in IP was significantly higher than SNP $(p<0.001)$ and MFP $(p=0.007)$. In our cohort, a total of 149 sRCC patients underwent NSS eventually, and $3(2.0 \%)$ of them showed positive SM in the following pathological findings (Table 3), 1 case in MFP and 2 cases in IP. No significant differences of SM (+) were discovered between SNP and MFP $(p=0.226)$ or between SNP and IP $(p=0.075)$. The situation of SM did

Table 3 The Relationship of PC, PC Invasion, PT stage, SM, and different growth patterns

\begin{tabular}{lllll}
\hline Growth pattern & SNP & MFP & IP \\
\hline PC & Absent & $17(3.9 \%)$ & $3(5.2 \%)$ & $28(43.8 \%)$ \\
& Present & $421(96.1 \%)$ & $55(94.8 \%)$ & $36(56.2 \%)$ \\
p value & & $<0.001$ & & \\
PC invasion & Invasion (-) & $325(77.2 \%)$ & $35(63.6 \%)$ & $0(0 \%)$ \\
& Invasion (+) & $90(21.4 \%)$ & $16(29.1 \%)$ & $8(22.2 \%)$ \\
& Invasion (++) & $6(1.4 \%)$ & $4(7.3 \%)$ & $28(77.8 \%)$ \\
p value & & $<0.001$ & & \\
pT stage & T1a & $436(99.5 \%)$ & $55(94.8 \%)$ & $50(78.1 \%)$ \\
& T3a & $2(0.5 \%)$ & $3(5.2 \%)$ & $14(21.9 \%)$ \\
$\boldsymbol{p}$ value & & $<0.001$ & & \\
SM & $(+)$ & $0(0 \%)$ & $1(3.8 \%)$ & $2(5.9 \%)$ \\
& $(-)$ & $89(100 \%)$ & $25(96.2 \%)$ & $32(94.1 \%)$ \\
$\boldsymbol{p}$ value & & 0.088 & & \\
\hline PC Pseudocaps & SNP & &
\end{tabular}

$P C$ Pseudocapsule, SNP A single nodular pattern, MFP A multinodular fusion pattern, IP An infiltration pattern; Invasion (-), PC intact and free from invasion; Invasion (+), PC with neoplastic infiltration on the parenchymal kidney with no invasion beyond it; Invasion (++), PC with neoplastic infiltration and invasion beyond it. $p T$ Pathologic tumor, SM, Surgical margins not seem to vary across the three growth patterns $(p=$ 0.088 ), while these data were only available for 149 cases, and only 3 patients were SM (+).

\section{Survival outcomes}

The median follow-up time was 62.7 months, and there were 64 deaths and 57 cancer-specific deaths. Among all the cancer-specific deaths, 3 (5.3\%) deaths were caused by local recurrence, and others were caused by metastasis. Thirty-one (54.4\%), 5 (8.8\%), $2(3.5 \%)$, and $1(1.8 \%)$ deaths were caused by metastasis to single organ, including lung, bone, liver, and brain, respectively. Fifteen (26.3\%) deaths were caused by distant metastasis where more than one organ. We calculated and compared the 5-year OS and CSS in different morphological growth patterns, PC status, and $\mathrm{pT}$ stage. For morphological growth patterns, the 5-year OS were $90.2 \%, 87.9 \%$, and $73.4 \%$ in SNP, MFP, and IP (Fig. 3A), and the 5-year CSS were 91.5\%, 91.4\%, and 76.2\%, respectively (Fig. 3B). There were statistical differences of the 5-year OS ( $p=$ $0.0002)$ and the 5 -year CSS $(p=0.0003)$ between the three different growth patterns. The 5-year OS $(p<$ $0.0001)$ and CSS $(p<0.0001)$ in SNP were significantly higher than that in IP (not shown in the table). For PC status, the 5-year OS were $93.1 \%, 85.1 \%$, and $73.7 \%$ in invasion (-), invasion $(+)$, and invasion $(++)$ (Fig. 3C), and the 5-year CSS were $94.1 \%, 86.8 \%$, and $76.2 \%$, respectively (Fig. 3D). There were statistical differences of the 5-year OS $(p<0.0001)$ and the 5-year CSS $(p<$ $0.0001)$ between PC status. The 5 -year OS and CSS in invasion $(++)$ and invasion $(+)$ were significantly higher than that in invasion (-) (not shown in the table). For the p $\mathrm{T}$ stage, the 5 -year OS were $89.1 \%$ and $57.9 \%$ in pT1a and PT3a (Fig. 3E), and the 5-year CSS were 90.7\% and $62.7 \%$, respectively (Fig. 3F). There were statistical differences of them between the pT1a and pT3a stage. For stratified analysis, older people had poor 5-year OS $(p=0.0003)$ and CSS $(p=0.0017)$ with statistical differences than young (Fig. 3G, H).

\section{Discussion}

At present, $\operatorname{sRCC}(\leq 4 \mathrm{~cm})$ is generally considered to be well differentiated, with low clinical stage and better prognosis. Several studies have shown that NSS could provide equally effective local control and oncologic safety as compared with RN for treating sRCC [9-11]. In addition, some reports have also revealed that NSS could offer local tumor control equivalent to $\mathrm{RN}$, even for RCC of more than $4 \mathrm{~cm} \mathrm{[12-14].} \mathrm{One} \mathrm{meta-analysis} \mathrm{in-}$ dicated that, as compared with RN, NSS reduced the incidence of post-operative renal complication by $61 \%$, and the mortality of patients by $19 \%$ [15]. These advantages make NSS become the primary treatment for sRCC currently. Nevertheless, some sRCC masses with 


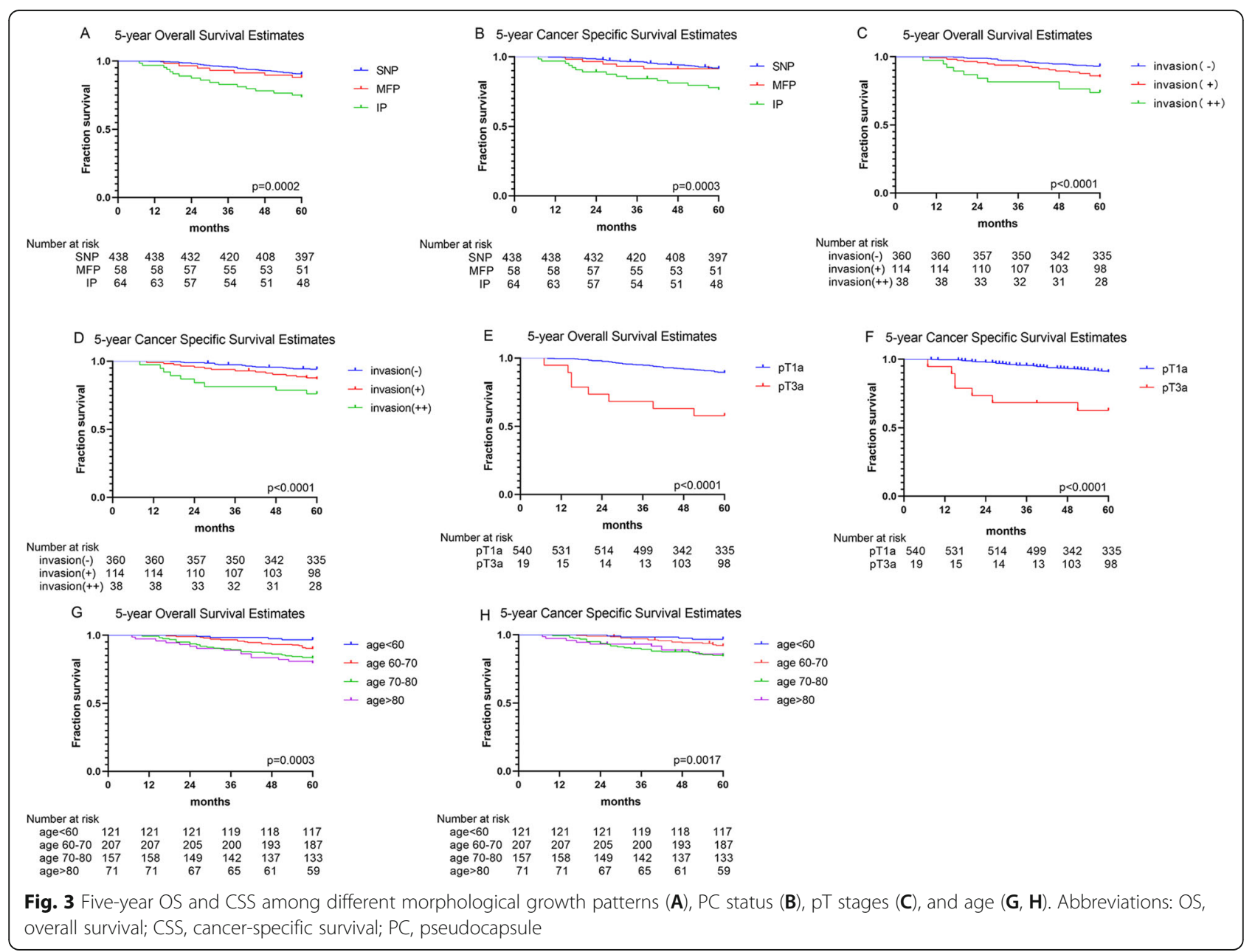

an infiltrative growth pattern show an aggressive clinical course and high tendency for distant metastasis. It is therefore extremely important to systematically study the histological characteristics of sRCC and to investigate the appropriate operational mode.

Akitoshi et al. reported that the growth pattern could be a predictive parameter for small clear cell RCC [16]; moreover, in their subsequent study, they demonstrated that the infiltrative growth pattern was an independent risk factor for disease-free survival (DFS) and CSS even in advanced cases [3]. In our study, we divided the growth patterns of sRCC into three groups: SNP, MFP, and IP, and we found most tumors (78.2\%) consist of a single mass. Peritumoral PC is mainly composed of connective fibrous tissue with the mean thickness of 0.39 $\mathrm{mm}$ (SD: 0.33; median: 0.58; range: $0.2-1.0 \mathrm{~mm}$ ). Some researchers supposed that it was a kind of protective manner to confine tumor growth and proliferation, because inflammatory layer consisted of lymphocytes, and plasmocytes sometimes could also be found between PC and normal parenchyma [17]. Minervini et al. analyzed 90 cases of pT1 stage RCC tumors which underwent enucleation and found complete PC was present in 67\% of tumors, and incomplete PC or PC infiltrated by cancer cells was detected in the rest of the samples [18]. Our study showed that 360 (64.3\%) cases had intact PC, and the total proportion of PC invaded by tumor cells in IP (100\%) was remarkably higher than that of the other two growth patterns. Accordingly, tumor enucleation is not recommended in sRCC of IP owing to the high risk of incomplete excision, so extending the scope of resection around the tumor is highly essential.

To prevent the risk of local recurrence, the excision of a minimal and visible margin of normal-appearing parenchyma around the tumor is regarded as the optimal surgical technique of NSS. However, whether or not to excise a rim of healthy parenchyma, theoretically adequate to avoid a positive SM and local recurrence, is still controversial. Marco et al. reviewed literatures published from January 2002 to May 2012 and discovered the overall incidence of positive SM ranges from 0 to $7 \%$, with no significant differences between the open, laparoscopic, and robot-assisted techniques [19, 20]. A very similar result was obtained in our study, with the 
incidence of positive SM of $2.0 \%$. Although no statistical differences of positive SM were discovered across the three growth patterns, the probability of positive SM in MFP and IP was evidently higher than that in SNP, as revealed in our study. The pathological stage of 19 (3.4\%) patients who were diagnosed pT1a stage before operation increased to the pT3a stage after surgery as the perirenal adipose tissue was invaded with tumor cells, suggesting that NSS might lead to positive SM of sRCC, though most neoplasms were limited in PC. Seongyub $\mathrm{Oh}$ reported that perirenal fat infiltration was an independent prognostic factor for predicting DFS in patients with tumors of $7 \mathrm{~cm}$ or less in size, and the presence of perirenal fat infiltration required stricter follow-up planning, even in small renal cell carcinoma [21]. Considering this, it is necessary to routinely excise the perirenal adipose tissue to reduce the possibility of local recurrence when undergoing NSS.

Therefore, the surgical margin (SM) is recommended to proceed along with the peritumoral PC for patients with SNP sRCC, because most SNP tumors were surrounded by complete PC. Tumor enucleation is also an available treatment for this kind of patient. $63.6 \%$ of MFP tumors have intact peritumoral PC, even if they are unlikely to grow in an irregular or polymorphy manner. For this pattern, tumor enucleation ought to be particularly choosy and a NSS margin with the thickness of 1$3 \mathrm{~mm}$ of renal parenchyma around the mass should be acceptable. Tumor enucleation is not suitable in IP sRCC in which almost all tumors possess no PC or incomplete PC infiltrated with cancer cells. Since the infiltrative depth of all tumors was confined in the range of $3 \mathrm{~mm}$ away from the peritumoral PC, as shown in the study, it is recommended to extend the optimal resection distance of NSS in IP sRCC more than $3 \mathrm{~mm}$ around the tumor surface, to acquire a histologic tumorfree margin. As for some infrequent cases, e.g., tumor cells invade deeply in normal kidney parenchyma over PC and sRCC with the presence of tumor multifocality or satellite lesions $[22,23]$, the recommended surgical measure of NSS is not appropriate any more, and radical nephrectomy should be considered [24, 25]. Our study also proved that prognostic outcome of SNP and MFP was significantly better than that in IP, and the infiltration level of PC invasion was closely related to the 5year OS and CSS.

There are some limitations of our study. First and uppermost, no reliable method is available to precisely distinguish different growth patterns before the operation at present, which confines the application of growth patterns in clinics. Second, the study was a retrospective, nonrandomized design which decreased the level of evidences. Third, pathologic data were collected from multiple centers over a long period, and the procedures for handling specimens were not uniform. Last, there is an inherent bias for the quality of specimens operated with different surgical manners that can affect the SM. Nevertheless, we believe that recognition of different growth patterns is useful for preoperative decision-making in the future. Large-scale studies are warranted to validate our growth pattern classification, to determine the optimal resection range.

\section{Conclusions}

According to our study, the growth pattern of sRCC could be divided into three morphological subtypes: SNP, MFP, and IP, and the results showed that incomplete peritumoral $\mathrm{PC}$, $\mathrm{pT}$ stage, and positive SM were statistically correlated with IP. As shown in the study, morphological growth patterns, if validated externally in a larger cohort, could be used as a valuable biomarker to help operating NSS in sRCC patients to avoid the risk of positive SM. The effectiveness of the growth pattern as a novel proposed parameter to direct NSS in sRCC patients deserves further exploration.

\begin{abstract}
Abbreviations
sRCC: Small renal cell carcinoma; NSS: Nephron-sparing surgery; RN: Radical nephrectomy; PC: Pseudocapsule; SM: Surgical margin; RCC: Renal cell carcinoma; SNP: Single nodular pattern; MFP: Multinodular fusion pattern; IP: Infiltration pattern; OS: Overall survival; CSS: Cancer-specific survival; DFS: Disease-free survival
\end{abstract}

\section{Acknowledgements}

Not applicable

\section{Authors' contributions}

GL, TFX, KRW, and CHW designed the study and edited the manuscript. RYZ and CZY collected the data and wrote the manuscript. AXW, GL, and KRW collected and analyzed the data. All authors read and approved the final manuscript.

\section{Funding}

This work was funded by Scientific research projects of the Inner Mongolian higher educational system (NJZY20197).

\section{Availability of data and materials}

The datasets used and analyzed during the current study are available from the corresponding author on reasonable request.

\section{Declarations}

Ethics approval and informed consent

The Institutional Review Board of Tianjin Medical University approved the study.

Informed consent was obtained from all the patients or their guardians.

Consent for publication

The written consent is available for review by the chief editor.

\section{Competing interests}

The authors declare that they have no competing interests.

\section{Author details}

'Department of Urology, The Second Hospital of Tianjin Medical University, Tianjin Institute of Urology, Tianjin 300211, China. ${ }^{2}$ Department of Reproductive Health, W.F. Maternal and Child Health Hospital, Weifang 261000, Shandong Province, China. ${ }^{3}$ Department of Pathology, The Affiliated Hospital of Jining Medical University, Jining, Shandong, China. ${ }^{4}$ Department 
of Pathology, The Second Hospital of Tianjin Medical University, Tianjin, China. ${ }^{5}$ Tianjin Baodi Hospital of Tianjin Medical University, Tianjin 301800, China. ${ }^{6}$ Department of Urology, Affiliated Hospital of Chifeng University, Chifeng, China.

\section{Received: 19 May 2021 Accepted: 20 August 2021}

Published online: 28 August 2021

\section{References}

1. Minervini A, Rosaria Raspollini M, Tuccio A, Di Cristofano C, Siena G, Salvi M, et al. Pathological characteristics and prognostic effect of peritumoral capsule penetration in renal cell carcinoma after tumor enucleation. Urol Oncol. 2014;32(1):50.e15-22.

2. Ljungberg B, Bensalah K, Canfield S, Dabestani S, Hofmann F, Hora M, et al. EAU guidelines on renal cell carcinoma: 2014 update. Eur Urol. 2015;67(5): 913-24. https://doi.org/10.1016/j.eururo.2015.01.005.

3. Fukatsu A, Tsuzuki T, Sassa N, Nishikimi T, Kimura T, Majima T, et al. Growth pattern, an important pathologic prognostic parameter for clear cell renal cell carcinoma. Am J Clin Pathol. 2013;140(4):500-5. https://doi.org/10.13 09/AJCPIMPE6ZFT8AME.

4. Jacob JM, Williamson SR, Gondim DD, Leese JA, Terry C, Grignon DJ, et al. Characteristics of the Peritumoral Pseudocapsule Vary Predictably With Histologic Subtype of T1 Renal Neoplasms. Urology. 2015;86(5):956-61. https://doi.org/10.1016/j.urology.2015.06.015

5. Volpe A, Bollito E, Bozzola C, Di Domenico A, Bertolo R, Zegna L, et al. Classification of Histologic Patterns of Pseudocapsular Invasion in OrganConfined Renal Cell Carcinoma. Clin Genitour Cancer. 2016;14(1):69-75. https://doi.org/10.1016/j.clgc.2015.07.020.

6. Steinestel J, Steffens S, Steinestel K, Schrader A. Positive surgical margins in nephron-sparing surgery: risk factors and therapeutic consequences [J]. World J Surg Oncol. 2014;12(1):252. https://doi.org/1 0.1186/1477-7819-12-252.

7. Li QL, Guan HW, Zhang QP, Zhang LZ, Wang FP, Liu YJ. Optimal margin in nephron-sparing surgery for renal cell carcinoma $4 \mathrm{~cm}$ or less. Eur Urol. 2003:44(4):448-51. https://doi.org/10.1016/S0302-2838(03)00310-5.

8. Kang HW, Lee SK, Kim WT, Yun SJ, Lee SC, Kim WJ, et al. Surgical margin does not influence recurrence rate in $\mathrm{p} T 1$ clear cell renal cell carcinoma after partial nephrectomy: A multicenter study. J Surg Oncol. 2016;114(1): 70-4. https://doi.org/10.1002/jso.24259.

9. Uzzo RG, Novick AC. Nephron sparing surgery for renal tumors: indications, techniques and outcomes. J Urol. 2001;166(1):6-18. https://doi.org/10.1016/ S0022-5347(05)66066-1.

10. Ficarra V, Secco S, Fracalanza S, Novara G, Gidaro S, Cindolo L, et al. Expanding indication for elective nephron-sparing surgery in renal cell carcinoma. Archivio italiano di urologia, andrologia : organo ufficiale [di] Societa italiana di ecografia urologica e nefrologica. 2009;81(2):86-90.

11. $X u J, X u S, Y a o B, X u R, X u Y$, Sun F, et al. Segmental artery clamping versus main renal artery clamping in nephron-sparing surgery: updated metaanalysis. World J Surg Oncol. 2020;18(1):210. https://doi.org/10.1186/s12957020-01990-w.

12. Antonelli A, Cozzoli A, Nicolai M, Zani D, Zanotelli T, Perucchini L, et al. Nephron-sparing surgery versus radical nephrectomy in the treatment of intracapsular renal cell carcinoma up to $7 \mathrm{~cm}$. Eur Urol. 2008;53(4):803-9. https://doi.org/10.1016/j.eururo.2007.11.007.

13. Alanee S, Nutt M, Moore A, Holland B, Dynda D, Wilber A, et al. Partial nephrectomy for $\mathrm{T} 2$ renal masses: contemporary trends and oncologic efficacy. Int Urol Nephrol. 2015;47(6):945-50. https://doi.org/10.1007/s11255015-0975-3.

14. Benoit T, Nouhaud FX, Roumiguie M, Merigot De Treigny O, Thoulouzan M, Doumerc $\mathrm{N}$, et al. Does a tumor size higher than $7 \mathrm{~cm}$ impact partial nephrectomy outcomes for the treatment of renal cancer? Progres en urologie : journal de l'Association francaise d'urologie et de la Societe francaise d'urologie. 2015;25(3):138-44. https://doi.org/10.1016/j.purol.2 014.11.007.

15. Kim SP, Thompson RH, Boorjian SA, Weight CJ, Han LC, Murad MH, et al Comparative effectiveness for survival and renal function of partial and radical nephrectomy for localized renal tumors: a systematic review and meta-analysis. J Urol. 2012;188(1):51-7. https://doi.org/10.1016/j.juro.2012.03. 006 .

16. Nishikimi T, Tsuzuki T, Fujita T, Sassa N, Fukatsu A, Katsuno S, et al. The postoperative pathological prognostic parameters of clear cell renal cell carcinoma in pT1a cases. Pathol Int. 2011;61(3):116-21. https://doi.org/1 0.1111/j.1440-1827.2010.02633.x.

17. Xiong ZQ, Zheng J, Feng CC, Bao Y, Ding Q, Fang ZJ. Low local metastatic rate may widen indication of nephron-sparing surgery for renal cell carcinoma. Ann Diagn Pathol. 2012;16(3):190-5. https://doi.org/10.1016/j.a nndiagpath.2011.10.002

18. Minervini A, di Cristofano C, Lapini A, Marchi M, Lanzi F, Giubilei G, et al. Histopathologic analysis of peritumoral pseudocapsule and surgical margin status after tumor enucleation for renal cell carcinoma. Eur Urol. 2009;55(6): 1410-8. https://doi.org/10.1016/j.eururo.2008.07.038.

19. Borghesi M, Brunocilla E, Schiavina R, Martorana G. Positive surgical margins after nephron-sparing surgery for renal cell carcinoma: incidence, clinical impact, and management. Clin Genitour Cancer. 2013;11(1):5-9. https://doi. org/10.1016/j.clgc.2012.09.010.

20. Shen $\mathrm{Z}$, Xie L, Xie W, Hu H, Chen $T$, Xing $C$, et al. The comparison of perioperative outcomes of robot-assisted and open partial nephrectomy: a systematic review and meta-analysis. World J Surg Oncol. 2016;14(1):220. https://doi.org/10.1186/s12957-016-0971-9.

21. Oh S, Yoon J, Kang D, Cho HL, Chung Jl. Prognostic significance of perirenal infiltration in renal cell carcinoma $(<7 \mathrm{~cm})$. Yonsei Med J. 2012:53(5):940-3. https://doi.org/10.3349/ymj.2012.53.5.940.

22. Richstone L, Scherr DS, Reuter VR, Snyder ME, Rabbani F, Kattan MW, et al. Multifocal renal cortical tumors: frequency, associated clinicopathological features and impact on survival. J Urol. 2004;171(2 Pt 1):615-20. https://doi. org/10.1097/01.ju.0000106955.19813.f6.

23. Sorbellini M, Bratslavsky G. Decreasing the indications for radical nephrectomy: a study of multifocal renal cell carcinoma. Front Oncol. 2012; 2:84.

24. Janssen M, Linxweiler J, Philipps I, Bütow Z, Siemer S, Stöckle M, et al. Kidney autotransplantation after nephrectomy and work bench surgery as an ultimate approach to nephron-sparing surgery. World J Surg Oncol. 2018;16(1):35. https://doi.org/10.1186/s12957-018-1338-1.

25. Zhang F, Gao S, Chen XN, Wu B. Clampless and sutureless laparoscopic partial nephrectomy using monopolar coagulation with or without $\mathrm{N}$-butyl2-cyanoacrylate. World J Surg Oncol. 2019;17(1):72. https://doi.org/10.1186/ s12957-019-1614-8.

\section{Publisher's Note}

Springer Nature remains neutral with regard to jurisdictional claims in published maps and institutional affiliations.
Ready to submit your research? Choose BMC and benefit from:

- fast, convenient online submission

- thorough peer review by experienced researchers in your field

- rapid publication on acceptance

- support for research data, including large and complex data types

- gold Open Access which fosters wider collaboration and increased citations

- maximum visibility for your research: over $100 \mathrm{M}$ website views per year

At $\mathrm{BMC}$, research is always in progress.

Learn more biomedcentral.com/submissions 